Artículo científico

Volumen 30(3):783-802. Septiembre-diciembre, 2019 e-ISSN 2215-3608, doi:10.15517/am.v30i3.36312 http://www.revistas.ucr.ac.cr/index.php/agromeso

\title{
Intensidad de pastoreo sobre perfil lipídico en leche bovina en el trópico seco colombiano $^{1}$
}

\section{Grazing intensity on the lipid profile in bovine milk in the Colombian dry tropic}

\author{
José Edwin Mojica-Rodríguez ${ }^{2}$,Edwin Castro-Rincón ${ }^{3}$, Juan Evangelista Carulla-Fornaguera ${ }^{4}$, \\ Carlos Eduardo Lascano-Aguilar ${ }^{4}$
}

1 Recepción: 28 de febrero, 2019. Aceptación: 6 de junio, 2019. Este trabajo formó parte de la tesis de doctorado "Evaluación de la alimentación con forrajes tropicales sobre la producción y calidad composicional de la leche en vacas doble propósito del trópico seco colombiano" financiada por la Corporación Colombiana de Investigación Agropecuaria (AGROSAVIA).

2 Corporación Colombiana de Investigación Agropecuaria (AGROSAVIA). Red de Ganadería y Especies Menores. CI Motilonia. Km 5 vía a Becerril - Agustín Codazzi. Cesar. Colombia. jmojica@agrosavia.co (https://orcid.org/0000-0001-7751-8631).

3 Corporación Colombiana de Investigación Agropecuaria (AGROSAVIA). Red de Ganadería y Especies Menores. CI Obonuco. Km 5 vía a Pasto - Obonuco. Nariño. Colombia. ecastro@agrosavia.co (https://orcid.org/0000-0001-9841-8242).

4 Universidad Nacional de Colombia, Facultad de Medicina Veterinaria y Zootecnia, Sede Bogotá. Cra. 45. No. 26 - 85. Colombia. jecarullaf@ unal.edu.co, cmlascanoa@unal.edu.co

\section{Resumen}

Introducción. Se ha sugerido que el perfil lipídico en la leche bovina afecta la salud humana y se ha identificado que el ácido linoleico conjugado (ALC c9 t11) podría tener efectos anticarcinogénicos. En trópico alto se ha investigado el efecto de la alimentación sobre el perfil lipídico de la leche, pero pocos estudios se han hecho en trópico bajo. Objetivo. El objetivo fue evaluar el efecto de tres intensidades de pastoreo (1, 2 y 3 animales ha-1) en pasto Guinea cv. Tanzania (Megathyrsus maximus) sobre la producción, composición y perfil lipídico en la leche de vacas mestizas en diferentes tercios de lactancia. Materiales y métodos. De septiembre a octubre de 2013, se seleccionaron dos grupos de nueve animales (tres vacas en cada tercio de lactancia) y se asignó una vaca por tercio de lactancia a cada intensidad de pastoreo (tratamiento), durante 42 días de evaluación, en un diseño de cuadrado latino 3 x 3 replicado. Resultados. La producción de leche fue similar $(p>0,05)$ entre tratamientos y fue mayor $(p<0,05)$ en vacas en inicio de lactancia. Los tratamientos no afectaron $(p>0,05)$ la composición de la leche, pero el tercio de lactancia tendió $(\mathrm{p}<0,10)$ a incrementar la concentración de sólidos totales y grasa. La grasa de la leche bovina en el pasto manejado con intensidad de pastoreo de 2,0 y 3,0 animales ha ${ }^{-1}$ tuvo una concentración mayor $(\mathrm{p}<0,05)$ de ALC

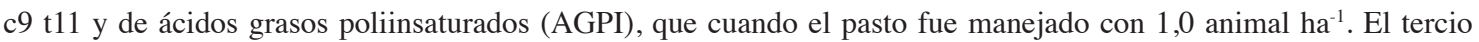
de lactancia no afectó ( $p>0,05)$ la concentración de ALC y AGPI. Conclusión. El manejo del cultivar Tanzania con intensidades de pastoreo de 2,0 y 3,0 animales ha-1 ${ }^{-1}$ resultó en las concentraciones más altas de ALC (c9 t11) y AGPI en la grasa de la leche, lo cual podría tener efectos positivos en salud humana.

Palabras clave: ácidos grasos, alimentación animal, gramíneas forrajeras, razas doble propósito. 


\begin{abstract}
Introduction. It has been suggested that the lipid profile in bovine milk affects human health, and it has been identified that conjugated linoleic acid (C9 t11 ALC) could have anticarcinogenic effects.In the high tropics the effect of feeding on lipid profile of milk has been investigated, but few studies have been done in the low tropics. Objective. The objective was to evaluate the effect of three grazing intensities $\left(1,2\right.$ and 3 animals ha $\left.{ }^{-1}\right)$ in Guinea cv Tanzania (Megathyrsus maximus) on the production, composition and lipid profile in the milk of cross breed cows in different thirds of lactation. Materials and methods. From september to october 2013, two groups of nine animals (three cows in each third of lactation) were selected, and one cow per third of lactation was assigned to each grazing intensity (treatment), during 42 days of evaluation in a replicated 3 x 3 Latin Square design. Results. Milk production did not differ $(\mathrm{p}>0.05)$ among treatments and was higher $(\mathrm{p}<0.05)$ in cows in early lactation. The treatments did not affect $(p>0.05)$ the composition of the milk, but solids and fat concentration tended $(p<0.10)$ to increase with third of lactation. Bovine milk fat in pasture managed with grazing intensity of 2.0 and 3.0 animals ha ${ }^{-1}$ had a higher $(\mathrm{p}<0.05)$ concentration of CLA ( $\mathrm{c} 9 \mathrm{t} 11)$ and of polyunsaturated fatty acids (PUFA) than when the grass was managed with 1.0 animal ha ${ }^{-1}$. The third of lactation did not influence ( $\left.\mathrm{p}>0.05\right)$ the concentration of CLA (c9 t11) and PUFA. Conclusion. Management of the cv Tanzania with grazing intensities of 2.0 and 3.0 animals ha ${ }^{-1}$ resulted in the highest levels of CLA (c9 t11) and PUFA in milk fat, which could have positive effects on human health.
\end{abstract}

Keywords: fatty acids in bovine milk, animal feeding, feed grasses, dual purpose breeds.

\title{
Introducción
}

A pesar de que existe controversia sobre el efecto de los ácidos grasos saturados como factores de riesgo en la presentación de enfermedades cardiovasculares (Siri et al., 2010; Soedamah-Muthu et al., 2011; Huth y Park, 2012; Kratz et al., 2013), se acepta que algunos ácidos grasos poliinsaturados en la leche como el ácido linoleico conjugado (ALC c9 t11), pueden tener efectos positivos sobre la salud del ser humano (Jutzeler y Colombani, 2010; Dilzer y Park, 2012).

Los isómeros del ácido linoleico conjugado (ALC) se producen en el proceso de biohidrogenación ruminal de los ácidos linoleico (C18:2) y linolénico (C18:3) aportados por los alimentos (Bessa et al., 2000). En la leche bovina existen más de veinticuatro isómeros de ALC; y dentro de esos el c9 t11 y el t7 c9 constituyen la mayor proporción del total de ALC (Corl et al., 2001).

El efecto de factores de manejo del pastoreo tales como la oferta y la edad de rebrote del forraje, afectan el perfil de los ácidos grasos en la grasa láctea en bovinos alimentados con especies forrajeras de zonas templadas. Por ejemplo, una mayor oferta de gramíneas (Cenchrus clandestinus, Poa pratensis y Bromus inermis) en pastoreo incrementa la concentración de ALC (c9 t11) en la grasa de la leche de vacas Holstein (Stanton et al., 1997; Dhiman et al., 1999), y la utilización de forraje joven incrementa la concentración de ALC (c9 t11) en la grasa de la leche de vacas Tarentaise y Montbéliarde (Ferlay et al., 2006).

El efecto de la intensidad de pastoreo mediante la modificación de la carga animal por hectárea se ha evaluado sobre la producción y composición de la leche en vacas de lechería especializada. Al respecto, McDonald et al. (2008) observaron una disminución lineal en la producción de leche y en el porcentaje de proteína en la leche de las vacas, al incrementar la carga animal $\left(2,2 ; 2,7 ; 3,1 ; 3,7\right.$ y 4,3 vacas ha $\left.{ }^{-1}\right)$. En un meta-análisis de la relación entre la carga animal y la productividad de leche se observó que por cada aumento en un animal por hectárea hubo una reducción en la producción diaria de leche por vaca de 7,8 \% y un aumento en 20,1 \% por unidad de área (McCarthy et al., 2011). 
En Colombia, la mayoría de los estudios se han realizado en lechería especializada del trópico alto. Por ejemplo, Aguilar et al. (2009) encontraron que el ALC (c9 t11) aumentó de 14,4 a 22,4 $\mathrm{mg} \mathrm{g}^{-1}$ de grasa en la leche de vacas Holstein al disminuir la edad de rebrote de 70 a 50 días en pasto kikuyo. En otro trabajo, en la Sabana de Bogotá, León (2011) encontró una mayor concentración (25,1 $\mathrm{mg} \mathrm{g}^{-1}$ de grasa) de ALC (c9 t11) en la leche de vacas Holstein

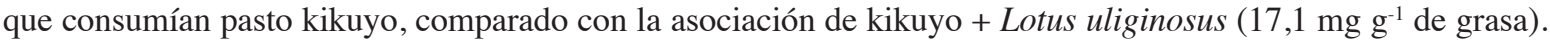

En lecherías de la microrregión Valle del Cesar, correspondiente al trópico seco de Colombia, el pasto Megathyrsus maximus (Guinea) cv. Tanzania es la gramínea introducida que más se utiliza en sistemas ganaderos doble propósito y que se caracteriza por alta producción de forraje y buen valor nutricional (Mojica et al., 2013). En la literatura revisada no se encontraron estudios en los que se haya evaluado el efecto de la intensidad de pastoreo, que modifica la oferta de forraje, sobre la concentración de ácidos grasos poliinsaturados en la leche de vacas en sistemas doble propósito alimentadas con forrajes tropicales.

El objetivo del presente trabajo fue evaluar el efecto de tres intensidades de pastoreo (1,2 y 3 animales ha-1) en pasto Guinea cv. Tanzania (Megathyrsus maximus) sobre la producción, composición y el perfil lipídico en la leche de vacas Gyr x Pardo Suizo en diferentes tercios de lactancia.

\section{Materiales y métodos}

\section{Localización}

El estudio se desarrolló en la Finca San Carlos, ubicada a 9 $50^{\circ}$ ' 19" de latitud norte y $73^{\circ} 22^{\prime}$ '54" de longitud oeste en el Municipio de San Diego en la microrregión Valle del Cesar del Departamento del Cesar, Colombia. En la zona se presenta una temperatura entre 28 y $30^{\circ} \mathrm{C}$, humedad relativa de 70 a $75 \%$, precipitación de 1100 a 1300 $\mathrm{mm}$, promedios multianuales (CORPOICA, 2017), con distribución bimodal en los meses de mayo a junio y de septiembre a diciembre (Pulido et al., 2002). La zona presenta suelos superficiales a profundos, bien drenados, de fertilidad moderada a alta característicos de la zona agroecológica tipo cj (Pulido et al., 2000). El estudio se realizó en época de lluvias durante los meses de septiembre (263 mm total de precipitación) y octubre (211 mm total de precipitación) del año 2013.

\section{Tratamientos}

Se evaluaron tres intensidades de pastoreo sobre Megathyrsus maximus (Guinea) cv. Tanzania, mediante el empleo de 1, 2 y 3 animales ha ${ }^{-1}$ (tratamientos), las cuales generaron ofertas promedio de 23,8; 12,5 y 6,6 kg MS hojas $100 \mathrm{~kg}^{-1}$ peso vivo día ${ }^{-1}$, respectivamente. Para generar los tres tratamientos se utilizaron 5,5 ha en total, que fueron distribuidas en 3,$0 ; 1,5$ y 1,0 ha, para la intensidad baja $\left(1,0\right.$ animal ha $\left.{ }^{-1}, \mathrm{~T} 1\right)$, intermedia $\left(2,0\right.$ animales ha ${ }^{1}$, T2) y alta (3,0 animales ha-1 $\mathrm{T} 3)$, respectivamente, con dos repeticiones por tratamiento. El área en cada tratamiento de intensidad de pastoreo se dividió en dos parcelas de 1,5; 0,75 y 0,5 ha, siendo la primera para acostumbramiento (siete días) y la segunda para realizar mediciones en los animales (siete días).

El periodo de acostumbramiento fue de siete días, identificado como apropiado para evaluar el efecto de dietas de vacas en pastoreo sobre la producción, composición y concentración de AG en la grasa de la leche (Jeffery 1970; Stoobs y Sandland, 1972; Elgersma et al., 2004; Rego et al., 2016).

\section{Establecimiento y manejo de la gramínea}

El suelo donde se realizó el experimento presentó una textura franco-arenosa, con pH entre 6,3 a 6,6; materia orgánica de 0,5 a $1,5 \%$; sin aluminio ni salinidad (Cuadro 1) y con buen drenaje. 
Cuadro 1. Análisis de suelo en los lotes experimentales (valores promedio). San Diego, Departamento del César, Colombia, septiembre-octubre. 2013.

Table 1. Soil analysis in the experimental plots (mean values). San Diego, Cesar Department. Colombia, September-October. 2013.

\begin{tabular}{lc}
\hline Componente & Valor \\
\hline $\mathrm{pH}$ & 6,4 \\
Conductividad eléctrica $\left(\mathrm{ds} \mathrm{m}^{-1}\right)$ & 0,87 \\
Materia orgánica $\left({\left.\mathrm{g} 100 \mathrm{~g}^{-1}\right)}^{-1,2}\right.$ \\
Calcio $\left(\mathrm{cmol} \mathrm{kg}^{-1}\right)$ & 18,75 \\
Magnesio $\left(\mathrm{cmol} \mathrm{kg}^{-1}\right)$ & 1,86 \\
Potasio $\left(\mathrm{cmol}\left(\mathrm{kg}^{-}\right)\right.$ & 0,49 \\
Sodio $\left(\mathrm{cmol}\left(\mathrm{kg}^{-}\right.\right.$ & $<0,12$ \\
Capacidad de intercambio catiónico efectiva & 21,43 \\
Hierro $\left(\mathrm{mg} \mathrm{kg}^{-1}\right)$ & 31,52 \\
Fósforo $\left(\mathrm{mg} \mathrm{kg}^{-1}\right)$ & 138,3 \\
Azufre $\left(\mathrm{mg} \mathrm{kg}^{-1}\right)$ & 12,6 \\
Manganeso $\left(\mathrm{mg} \mathrm{kg}^{-1}\right)$ & 1,90 \\
Zinc $\left(\mathrm{mg} \mathrm{kg}^{-1}\right)$ & $<1,0$ \\
Cobre $\left(\mathrm{mg} \mathrm{kg}^{-1}\right)$ & 3,62 \\
Boro $\left(\mathrm{mg} \mathrm{kg}^{-1}\right)$ & 0,32 \\
\hline
\end{tabular}

Para la preparación de terreno se realizó un pase de cincel, dos pases de rastra y un pase de pulidor. La siembra de la gramínea se realizó al voleo en forma manual con una densidad de siembra de $8 \mathrm{~kg}_{\text {ha }}{ }^{-1}$ recomendada en la región.

Las malezas de hoja ancha, durante la fase de establecimiento de la gramínea, se controlaron en forma manual y con dos aplicaciones de 2,4 D diclorofenoxiacético $\left(31 \mathrm{ha}^{-1}\right)$. Al mes de emergencia de las plántulas, se aplicaron $40 \mathrm{~kg} \mathrm{ha}^{-1}$ de fosfato diamónico $\left(19,2 \mathrm{~kg} \mathrm{ha}^{-1} \mathrm{de}_{2} \mathrm{O}_{5}\right), 54,3 \mathrm{~kg} \mathrm{ha}^{-1}$ de urea $\left(25,0 \mathrm{~kg} \mathrm{ha}^{-1} \mathrm{de} \mathrm{N}\right)$ y $13 \mathrm{~kg} \mathrm{ha}^{-1} \mathrm{de}$ cloruro de potasio $\left(7,8 \mathrm{~kg} \mathrm{ha}^{-1}\right.$ de $\left.\mathrm{K}_{2} \mathrm{O}\right)$. Luego del establecimiento de la gramínea (seis meses) se realizó un corte de uniformización con guadaña de tractor y se aplicó la misma cantidad de urea y de cloruro de potasio utilizada en el establecimiento de la gramínea durante el tiempo de la evaluación. Los potreros tuvieron un periodo de descanso de veintiocho días y de siete días de ocupación durante la duración del experimento.

\section{Animales experimentales}

Se utilizaron dieciocho vacas Gyr x Pardo Suizo de segundo parto conformadas por dos grupos experimentales de nueve animales. Cada grupo estaba constituido por tres vacas en primer tercio ( $47 \pm 2$ días de lactancia), tres vacas en segundo tercio (148 \pm 3 días de lactancia) y tres vacas en último tercio de lactancia (196 \pm 3 días de lactancia). Se asignó al azar una vaca de cada tercio de lactancia en cada una de las intensidades de pastoreo. Los animales no se suplementaron con alimento balanceado.

El ordeño de las vacas se realizó con el apoyo de ternero. Se ordeñaron tres cuartos de la ubre y se dejó disponible un cuarto mamario para el consumo de leche por la cría durante treinta minutos. Para cuantificar la producción total de leche por vaca (vendible + consumida por la cría), se estimó la leche consumida por los terneros mediante la diferencia de peso antes del ordeño y treinta minutos después de haber mamado por medio de balanza electrónica. Posteriormente, los terneros se trasladaron a un potrero de pasto colosuana (Bothriochloa pertusa). 


\section{Variables medidas}

\section{En las pasturas}

Se evaluó el forraje en oferta y la composición botánica de las pasturas en cada periodo experimental, antes del ingreso de los animales a la parcela (Toledo y Schultze-Kraft, 1982). Además, se tomaron muestras de forraje, simulando el pastoreo (pluck) de los animales, y se secaron en horno durante $48 \mathrm{~h}$ a una temperatura de $55^{\circ} \mathrm{C}$ para su posterior análisis químico. En el laboratorio se midió proteína cruda (PC) (AOAC, 2010), fibra en detergente neutro (FDN) y fibra en detergente ácido (FDA) (Van-Soest et al., 1991), grasa total por extracción con éter (EE) (AOAC, 2010), degradabilidad in situ de la materia seca (DISMS) (Ørskov et al., 1980) y perfil de ácidos grasos por cromatografía de gases.

La concentración de ácidos grasos en el forraje cosechado (hojas) se estimó a partir del extracto etéreo y utilizando la ecuación de Allen (2000). La concentración de AG y el perfil lipídico se expresó en $\mathrm{g} \mathrm{kg}^{-1}$ de materia seca (MS).

La extracción y metilación de los ácidos grasos en los forrajes se realizó adaptando las técnicas descritas por Garcés y Mancha (1993) y por Yamasaki et al. (1999). Al forraje (50 mg) se le adicionaron $2150 \mu \mathrm{l}$ de metanol absoluto, $990 \mu \mathrm{l}$ de tolueno, $66 \mu \mathrm{l}$ de ácido sulfúrico al 99,9\%, $1000 \mu \mathrm{l}$ de $\mathrm{N}, \mathrm{N}$ dimetilformamida y $2 \mathrm{ml}$ de n-hexano; la mezcla se colocó en un baño térmico $\left(2 \mathrm{~h} \mathrm{a} 80{ }^{\circ} \mathrm{C}\right)$, se dejó en reposo (5 - $\left.10 \mathrm{~min}\right)$, se agitó y se recuperó el sobrenadante. El hexano del sobrenadante se evaporó mediante corriente de nitrógeno. Al residuo se le adicionaron $300 \mu \mathrm{l}$ de diclorometano y se llevó a un vial con inserto cónico. Los ésteres de ácidos grasos metilados (FAMES) de la grasa de la leche y del forraje se cuantificaron por cromatografía de gases. Se utilizó un cromatógrafo de gases con auto inyector AOC20i y auto muestreador AOC20C. Los FAMES fueron separados en columna capilar (Rt 2560; $100 \mathrm{~m}$ x 0,25 mm di x 0,2 $\mu \mathrm{m}$ espesor de la capa). Las temperaturas del inyector y del FID fueron $260{ }^{\circ} \mathrm{C}$ y $270{ }^{\circ} \mathrm{C}$, respectivamente. El programa de temperatura fue: $140{ }^{\circ} \mathrm{C}$ por $5 \mathrm{~min}$, se incrementó 4 ${ }^{\circ} \mathrm{C} \mathrm{min}^{-1}$ hasta $190{ }^{\circ} \mathrm{C}$ y se mantuvo por 32,5 min. El split ratio fue de 1: 100 y el He fue el gas de arrastre con una presión de 40,4 psi. Los tiempos de retención fueron comparados con estándares conocidos que contienen ácidos grasos de cadena par e impar desde 4 hasta 22 carbonos, incluyendo ALC c9 t11 y ácido transvaccénico (Food Industry FAMEX Mix cat 35007).

\section{En los animales}

En el periodo de medición se registró diariamente la producción individual de leche vendible (tres cuartos mamarios) y se corrigió por grasa al $4 \%$. En la leche se midió el contenido de proteína, grasa, lactosa, minerales y sólidos totales con un equipo autoanalizador de leche previamente calibrado. Además, se realizó extracción del suero de la leche con renina comercial para posterior análisis de nitrógeno ureico en leche (NUL) (Fawcett y Scott, 1960).

Para el análisis de ácidos grasos, la extracción de la grasa en la leche se realizó a través de modificaciones a las técnicas de separación mecánica descritas por Hurley et al. (1987) y Díaz et al. (2002). Se centrifugaron 100 $\mathrm{ml}$ de leche (15 min a $3000 \mathrm{rpm}$ ) y se retiró la fracción acuosa; el sobrenadante cremoso se mezcló con $15 \mathrm{ml}$ de solución detergente (50 g de hexametafosfato de sodio y $24 \mathrm{ml}$ de Tritón X100 disueltos en 11 de agua), se agitó, se colocó en baño térmico $\left(10 \min\right.$ a $\left.90{ }^{\circ} \mathrm{C}\right)$, nuevamente se agitó y se puso en baño térmico $\left(10\right.$ min a $\left.90{ }^{\circ} \mathrm{C}\right)$. La grasa de la capa superficial se retiró con una micropipeta y se almacenó a $-20{ }^{\circ} \mathrm{C}$. Se recolectaron $100 \mu \mathrm{lde}$ grasa y se solubilizaron en $900 \mu \mathrm{l}$ de diclorometano. Una alícuota de $20 \mu \mathrm{l}$ de esa mezcla, $20 \mu \mathrm{l}$ del reactivo de metil esterificación (0,2 M m-trifluorometilfenil-trimetilamonio hidróxido en metanol) (Alltech Associates Inc., Deerfield, IL, USA) y $160 \mu \mathrm{l}$ de diclorometano se adicionaron en un vial con inserto cónico. 


\section{Cálculos}

Los ácidos grasos de síntesis de novo, se cuantificaron mediante la suma de ácidos grasos desde cuatro hasta menos de dieciséis carbonos (Rico, 2013). Los ácidos grasos preformados se cuantificaron mediante la sumatoria de los ácidos grasos de más de dieciséis carbonos (Rico, 2013).

El índice de actividad delta 9 desaturasa, que indica la producción de ácidos insaturados (C14:1, C16:1, C18:1 y ALC c9 t11) a partir de sustratos (C14:0, C16:0, C18:0 y C18:1 t11), se calculó con la ecuación de Gagliostro et al. (2006).

El índice de aterogenicidad, que indica la probabilidad de presentación de ateroesclerosis, se calculó con base en la concentración de ácidos grasos de 12, 14 y 16 carbonos y la concentración de ácidos grasos insaturados (Ulbricht y Southgate, 1991).

El índice de trombogenicidad, que indica la probabilidad de presentación de trombosis coronaria en humanos, se calculó con base en la concentración de ácidos grasos de 14, 16 y 18 carbonos, la concentración de ácidos grasos monoinsaturados y poliinsaturados (Omega 3 y 6) (Ulbricht y Southgate, 1991).

\section{Diseño experimental y análisis estadístico}

Se utilizó un diseño de cuadrado latino 3 x 3 replicado, al que se asignaron vacas en tres estados de lactancia (Amezquita, 1999). Para las variables medidas en las pasturas el análisis de varianza se hizo con base en el modelo $\mathrm{Y}_{\mathrm{ijk}}=\mu+\alpha_{\mathrm{i}}+\varrho_{\mathrm{j}}+\beta_{\mathrm{k}}+(\varrho \beta)_{\mathrm{jk}}+\varepsilon_{\mathrm{ijk}}$, donde: $\mathrm{Y}_{\mathrm{ijk}}$ es la variable de interés, $\mu$ es el promedio general, $\alpha_{\mathrm{i}}$ es el efecto del cuadrado latino $(i=1,2), Q_{j}$ es el efecto del periodo experimental $(j=1$ a 3$), \beta_{k}$ es el efecto de la intensidad de pastoreo (tratamiento) $(\mathrm{k}=1$ a 3$),(\varrho \beta)_{\mathrm{jk}}$ es el efecto de la interacción periodo $\mathrm{x}$ intensidad de pastoreo ( $\mathrm{jk}=1$ a 9) y $\varepsilon_{\mathrm{ijk}}$ es el error residual.

En las variables medidas en animales se realizó un análisis de varianza empleando el modelo $Y_{\mathrm{ijkl}}=\mu+\alpha_{\mathrm{i}}+\varrho_{\mathrm{j}}+$ $\beta_{\mathrm{k}}+\theta_{1}+(\beta \theta)_{\mathrm{kl}}+\varepsilon_{\mathrm{ijkl}}$, donde: $\mathrm{Y}_{\mathrm{ijkl}}$ es la variable de interés, $\mu$ es el promedio general, $\alpha_{\mathrm{i}}$ es el efecto del cuadrado latino $(i=1,2), \varrho_{j}$ es el efecto del periodo experimental $\left(j=1\right.$ a 3 ), $\beta_{k}$ es el efecto de la intensidad de pastoreo (tratamiento) $(\mathrm{k}=1$ a 3$), \theta_{1}$ es el efecto del tercio de lactancia $(1=1$ a 3$),(\beta \theta)_{\mathrm{kl}}$ es el efecto de la interacción intensidad de pastoreo $\mathrm{x}$ tercio de lactancia $\left(\mathrm{kl}=1\right.$ a 9) y $\varepsilon_{\mathrm{ijkl}}$ es el error residual. Para el análisis se utilizó el PROC MIXED del software SAS versión 9.3 (SAS Institute Inc., 2011) y la comparación de medias se realizó con la prueba de Tukey con un nivel de significancia del $5 \%$.

\section{Resultados}

\section{Disponibilidad y composición botánica del forraje}

La oferta de materia seca verde (hojas + tallo) y de hojas expresadas en kilogramos por animal o por $100 \mathrm{~kg}$ de peso vivo por día, fueron diferentes $(\mathrm{p}<0,05)$ para las tres intensidades de pastoreo evaluadas. Sin embargo, aún en la intensidad alta, la oferta de MS verde y hojas no fue limitante para consumo. El pasto Guinea representó la principal gramínea (superior al $80 \%$ ) en las pasturas de todos los tratamientos evaluados. El pasto colosuana ( $B$. pertusa), gramínea naturalizada en la región, estuvo presente en las pasturas, pero su contribución a la biomasa comestible fue baja (máximo 11,8 \%) y similar $(\mathrm{p}>0,05)$ en las diferentes intensidades de pastoreo (Cuadro 2). 
Cuadro 2. Oferta de materia seca (MS), materia seca verde (MSV) y composición botánica en pastura de Guinea cv. Tanzania (Megathyrsus maximus), manejado con intensidades de pastoreo contrastantes en San Diego, Departamento del César, Colombia, septiembre-octubre. 2013.

Table 2. Dry matter supply (DM) green dry matter (GDM), and botanical composition in Guinea pasture cv. Tanzania (Megathyrsus maximus) managed with contrasting grazing intensities in San Diego, Cesar Department. Colombia, September-October. 2013.

\begin{tabular}{|c|c|c|c|c|c|}
\hline \multirow[t]{2}{*}{ Variable } & \multicolumn{3}{|c|}{ Intensidad de pastoreo (animales ha-1) } & \multirow[b]{2}{*}{ ESM } & \multirow[b]{2}{*}{$\mathbf{P}$} \\
\hline & Baja $(1,0)$ & Media $(2,0)$ & Alta $(3,0)$ & & \\
\hline kg MS hojas vaca-1 día ${ }^{-1}$ & $95,5^{\mathrm{a}}$ & $52,6^{\mathrm{b}}$ & $26,2^{\mathrm{c}}$ & 8,11 & 0,006 \\
\hline kg MS hojas $100 \mathrm{~kg}^{-1}$ peso vivo día ${ }^{-1}$ & $23,8^{\mathrm{a}}$ & $12,5^{\mathrm{b}}$ & $6,6^{\mathrm{c}}$ & 2,08 & 0,007 \\
\hline 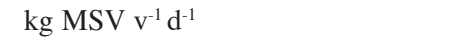 & $119,1^{\mathrm{a}}$ & $68,8^{\mathrm{b}}$ & $34,7^{\mathrm{c}}$ & 5,41 & 0,001 \\
\hline kg MSV $100 \mathrm{~kg}^{-1} \mathrm{PV} \mathrm{d}^{-1}$ & $29,7^{\mathrm{a}}$ & $16,4^{\mathrm{b}}$ & $8,7^{\mathrm{c}}$ & 1,37 & 0,0009 \\
\hline Relación hoja : tallo & 1,2 & 1,4 & 1,2 & 0,19 & 0,20 \\
\hline \multicolumn{6}{|l|}{ Composición botánica } \\
\hline Guinea $(\%)$ & 86,2 & 83,7 & 83,9 & 3,33 & 0,29 \\
\hline Colosuana $(\%)$ & 11,8 & 11,0 & 11,3 & 2,52 & 0,89 \\
\hline Leguminosas (\%) & 0,8 & 0,8 & 0,1 & 0,53 & 0,10 \\
\hline Malezas (\%) & 1,2 & 4,5 & 4,7 & 2,86 & 0,42 \\
\hline
\end{tabular}

ESM: error estándar de la media de los tratamientos. Letras diferentes en la misma fila indican diferencias significativas $(\mathrm{p}<0,05)$ según prueba de Tukey / ESM: standard error of the mean of the treatments. Different letters in the same row indicate significant differences $(\mathrm{p}<0.05)$ according to Tukey's test.

\section{Calidad del pasto Guinea cv. Tanzania}

No se presentaron diferencias $(\mathrm{p}>0,05)$ en el contenido de proteína cruda $(\mathrm{PC})$, en la concentración de fibra (FDN y FDA), en el extracto etéreo y la degradabilidad in situ de la materia seca del pasto Guinea cv. Tanzania en las diferentes intensidades de pastoreo (Cuadro 3). Se esperaba menores niveles de PC y digestibilidad del forraje en la intensidad de pastoreo baja, pero posiblemente por el tipo de muestreo simulando pastoreo (pluck) que se usó, se tendió a cosechar forraje con madurez similar en las tres intensidades de pastoreo impuestos.

\section{Perfil de ácidos grasos en pasto Guinea cv. Tanzania}

El contenido $\left(\mathrm{g} \mathrm{kg}^{-1} \mathrm{MS}\right)$ de ácidos grasos totales y la mayoría de AG individuales fueron similares $(\mathrm{p}>0,05)$ en el pasto Guinea cv. Tanzania sometido a las tres intensidades de pastoreo. Sin embargo, en la intensidad alta $\left(3,0\right.$ animales $\left.\mathrm{ha}^{-1}\right)$ la relación ácido linoleico/linolénico fue mayor $(\mathrm{p}<0,05)$ que en las otras dos intensidades de pastoreo. Asimismo, en la intensidad alta la relación linoleico/linolénico fue mayor $(\mathrm{p}<0,05)$ y el contenido de ácido linoleico $(\mathrm{C} 18: 2)$ tendió $(\mathrm{p}<0,10)$ a ser mayor. El contenido de precursores de ALC (linoleico + linolénico) fue numéricamente mayor, pero no significativo ( $p>0,05)$ (Cuadro 4$)$.

\section{Producción y composición de la leche}

No hubo efecto de la interacción intensidad de pastoreo $x$ tercio de lactancia $(\mathrm{p}>0,05)$ sobre la producción y composición de la leche. La producción de leche vendible, total por vaca (vendible + consumida por el ternero) 
Cuadro 3. Calidad nutricional del pasto Guinea cv. Tanzania (Megathyrsus maximus) manejado con intensidades de pastoreo contrastantes en San Diego, Departamento del César, Colombia, septiembre-octubre. 2013.

Table 3. Nutritional quality of Guinea cv. Tanzania (Megathyrsus maximus) grass managed with contrasting grazing intensities in San Diego, Cesar Department. Colombia, September-October. 2013.

\begin{tabular}{|c|c|c|c|c|c|}
\hline \multirow[b]{2}{*}{ Variable } & \multicolumn{3}{|c|}{ Intensidad de pastoreo (animales ha ${ }^{-1}$ ) } & \multirow[b]{2}{*}{ ESM } & \multirow[b]{2}{*}{$\mathbf{P}$} \\
\hline & Baja $(1,0)$ & Media $(2,0)$ & Alta $(\mathbf{3 , 0})$ & & \\
\hline $\mathrm{PC}(\%)$ & 12,9 & 14,9 & 12,3 & 1,38 & 0,14 \\
\hline FDN $(\%)$ & 66,1 & 67,6 & 66,8 & 1,38 & 0,30 \\
\hline FDA $(\%)$ & 39,4 & 39,4 & 38,5 & 1,79 & 0,40 \\
\hline $\mathrm{EE}(\%)$ & 1,9 & 2,3 & 2,9 & 1,12 & 0,28 \\
\hline DISMS (\%) & 58,8 & 63,0 & 62,0 & 3,61 & 0,35 \\
\hline
\end{tabular}

PC: proteína cruda. FDN: fibra en detergente neutro. FDA: fibra en detergente ácido. EE: extracto etéreo. DISMS: degradabilidad in situ de la materia seca. ESM: error estándar de la media de los tratamientos. Letras diferentes en la misma fila indican diferencias significativas $(\mathrm{p}<0,05)$ según prueba de Tukey / PC: crude protein. FDN: fiber in neutral detergent . FDA: fiber in acid detergent . EE: ethereal extract. DISMS: in situ degradability of dry matter. ESM: standard error of the mean of the treatments. Different letters in the same row indicate significant differences $(\mathrm{p}<0.05)$ according to Tukey's test.

y corregida por grasa al $4 \%$ fueron similares $(\mathrm{p}>0,05)$ en las diferentes intensidades de pastoreo, pero fueron mayores $(\mathrm{p}<0,05)$ en las vacas de primer tercio de lactancia en comparación con las vacas de segundo y último tercio (Cuadro 5).

La intensidad de pastoreo no afectó ( $p>0,05)$ la concentración de los componentes de la leche (Cuadro 6). Sin embargo, la concentración de sólidos totales y de grasa tendieron $(\mathrm{p}<0,10)$ a incrementarse a medida que progresó la lactancia. Los niveles de nitrógeno ureico en leche (NUL) que son reflejo de balance energía/proteína en la dieta, no variaron en forma significativa en función de la intensidad de pastoreo y tercio de lactancia (Cuadro 6).

\section{Perfil de ácidos grasos en la grasa de la leche}

Las concentraciones individuales de los ácidos grasos de cadena corta (C4 a C10), cadena media (C12 a C16) y de ácido esteárico $(\mathrm{C} 18)$ fueron similares $(\mathrm{p}>0,05)$ en la grasa de la leche de las vacas que consumieron pasto Guinea cv. Tanzania, manejado con tres intensidades de pastoreo. La sumatoria de las concentraciones de los ácidos grasos C12, C14 y C16 tendió a ser mayor $(\mathrm{p}<0,10)$ en la grasa de la leche de las vacas que pastorearon pasto Tanzania manejado con intensidad baja (Cuadro 7).

Las concentraciones de ácido oleico (C18:1) y ALC ( 99 t11) fueron mayores $(\mathrm{p}<0,05)$ en la grasa de la leche de las vacas en las intensidades de pastoreo intermedia $(2,0$ animales ha-1 $)$ y alta $(3,0$ animales ha-1). Las concentraciones de ácido linoleico $(\mathrm{C} 18: 2)$ y linolénico $(\mathrm{C} 18: 3)$ fueron mayores $(\mathrm{p}<0,05)$ en la grasa de la leche de las vacas en la intensidad alta $\left(3,0\right.$ animales ha $\left.{ }^{-1}\right)$ de pastoreo.

La concentración de ácidos grasos saturados fue mayor $(\mathrm{p}<0,05)$ en la grasa de la leche de las vacas que pastorearon en intensidad baja $\left(1,0\right.$ animales $\left.\mathrm{ha}^{-1}\right)$, pero la concentración de ácidos grasos insaturados fue mayor $(\mathrm{p}<0,05)$ en la grasa de la leche de las vacas en las intensidades media $\left(2,0\right.$ animales ha $\left.{ }^{-1}\right)$ y alta $\left(3,0\right.$ animales ha $\left.{ }^{-1}\right)$ de pastoreo (Cuadro 7).

La concentración de ácidos grasos de síntesis de novo fue similar $(\mathrm{p}>0,05)$ en las intensidades de pastoreo evaluadas, mientras que los ácidos grasos preformados tendieron $(\mathrm{p}<0,10)$ a ser menores en la carga media y alta. Asimismo, el índice de actividad de la delta 9 desaturasa fue mayor $(\mathrm{p}<0,05)$ en la grasa de la leche de las vacas 
Cuadro 4. Contenido de ácidos grasos totales y perfil de ácidos grasos en pasto Guinea cv. Tanzania (Megathyrsus maximus) manejado con intensidades de pastoreo contrastantes en San Diego, Departamento del César, Colombia, septiembre-octubre 2013.

Table 4. Total fatty acids content and fatty acid profile in Guinea cv. Tanzania (Megathyrsus maximus) grass managed with contrasting grazing intensities in San Diego, Cesar Department. Colombia, September-October. 2013.

\begin{tabular}{|c|c|c|c|c|c|}
\hline \multirow[b]{3}{*}{ Ácidos grasos } & \multicolumn{3}{|c|}{ Intensidad de pastoreo (animales ha $^{-1}$ ) } & \multirow[b]{2}{*}{ ESM } & \multirow[b]{2}{*}{$\mathbf{P}$} \\
\hline & Baja $(1,0)$ & Media $(2,0)$ & Alta $(3,0)$ & & \\
\hline & & & $\mathrm{g} \mathrm{kg}^{-1} \mathrm{MS}$ & & \\
\hline $\mathrm{AG}$ & 9,7 & 13,5 & 19,6 & 11,5 & 0,28 \\
\hline $\mathrm{C} 14: 0$ & 0,81 & 1,21 & 1,66 & 0,91 & 0,25 \\
\hline $\mathrm{C} 16: 0$ & 3,52 & 5,60 & 6,70 & 4,32 & 0,39 \\
\hline C18:0 & 0,28 & 0,44 & 0,61 & 0,48 & 0,51 \\
\hline C18:1 c9 & 0,88 & 0,65 & 0,69 & 1,43 & 0,20 \\
\hline $\mathrm{C} 18: 2$ c9 c12 & 0,58 & 0,67 & 1,59 & 0,69 & 0,09 \\
\hline $\mathrm{C} 18: 3 \mathrm{c} 9 \mathrm{c} 12 \mathrm{c} 15$ & 1,15 & 1,28 & 1,67 & 0,94 & 0,68 \\
\hline Precursores ${ }^{1}$ & 1,73 & 1,94 & 3,26 & 1,58 & 0,31 \\
\hline $\mathrm{C} 18: 2 / \mathrm{C} 18: 3$ & $0,50^{\mathrm{b}}$ & $0,52^{\mathrm{b}}$ & $0,94^{\mathrm{a}}$ & 0,21 & 0,03 \\
\hline
\end{tabular}

${ }^{1}$ Ácido linoleico + linolénico. AG: ácidos grasos totales. ESM: error estándar de la media de los tratamientos. Letras diferentes en la misma fila indican diferencias significativas $(\mathrm{p}<0,05)$ según prueba de Tukey / ${ }^{1}$ Linoleic acid + linolenic acid. AG: total fatty acids. ESM: standard error of the mean of the treatments. Different letters in the same row indicate significant differences $(\mathrm{p}<0.05)$ according to Tukey's test.

Cuadro 5. Producción de leche de vacas Gyr x Pardo Suizo de segundo parto en diferentes tercios de lactancia en pastoreo de Guinea cv. Tanzania (Megathyrsus maximus) en función de la intensidad de pastoreo y el tercio de lactancia en San Diego, Departamento del César, septiembre-octubre. 2013.

Table 5. Milk production of Gyr x Brown Swiss cows of second birth in different thirds of lactation in Guinea cv. Tanzania (Megathyrsus maximus) depending on the intensity of grazing and third of lactation in San Diego, Cesar Department. Colombia, September-October. 2013.

\begin{tabular}{|c|c|c|c|c|c|}
\hline \multirow[t]{2}{*}{ Variable } & \multicolumn{3}{|c|}{ Intensidad de pastoreo (animales ha $^{-1}$ ) } & \multirow[t]{2}{*}{ ESM } & \multirow[t]{2}{*}{$\mathbf{P}$} \\
\hline & Baja $(1,0)$ & Media $(2,0)$ & Alta $(3,0)$ & & \\
\hline Vendible (kg vaca ${ }^{-1}$ día $\left.^{-1}\right)$ & 4,6 & 4,5 & 4,3 & 0,99 & 0,58 \\
\hline Total $\left(k g\right.$ vaca-1 día $\left.^{-1}\right)$ & 6,7 & 6,7 & 6,2 & 1,03 & 0,26 \\
\hline Total LCG $4 \%\left(\mathrm{~kg} \mathrm{vaca}^{-1}\right.$ día $\left.^{-1}\right)$ & 7,3 & 7,1 & 6,5 & 1,64 & 0,31 \\
\hline \multirow[t]{2}{*}{ Total LCG $4 \%\left(\mathrm{~kg} \mathrm{vaca}^{-1} \mathrm{dí}^{-1}\right)$} & $7,3^{\mathrm{c}}$ & $14,1^{\mathrm{b}}$ & $19,4^{\mathrm{a}}$ & 3,20 & 0,006 \\
\hline & \multicolumn{3}{|c|}{ Tercio de lactancia } & & \\
\hline Variable & Primer & Segundo & Tercero & ESM & $\mathbf{P}$ \\
\hline Vendible (kg vaca ${ }^{-1}$ día $\left.^{-1}\right)$ & $5,8^{\mathrm{a}}$ & $3,7^{\mathrm{b}}$ & $4,1^{\mathrm{b}}$ & 0,69 & 0,0001 \\
\hline Total $\left(\mathrm{kg} \mathrm{vaca}{ }^{-1}\right.$ día $\left.^{-1}\right)$ & $8,2^{\mathrm{a}}$ & $5,4^{\mathrm{b}}$ & $5,9^{\mathrm{b}}$ & 0,90 & 0,0001 \\
\hline Total LCG $4 \%\left(\mathrm{~kg} \mathrm{vaca}^{-1}\right.$ día $\left.^{-1}\right)$ & $8,5^{\mathrm{a}}$ & $5,9^{\mathrm{b}}$ & $6,7^{\mathrm{b}}$ & 0,80 & 0,0001 \\
\hline Total LCG $4 \%\left(\mathrm{~kg} \mathrm{vaca}^{-1} \mathrm{dí}^{-1}\right)$ & $16,5^{\mathrm{a}}$ & $11,6^{\mathrm{b}}$ & $12,6^{b}$ & 1,56 & 0,0001 \\
\hline
\end{tabular}

ESM: error estándar de la media de los tratamientos. LCG: leche corregida por grasa $4 \%$; LCG: $(0,4$ x PLT $)+15$ x kg G. PLT: producción de leche total, G: grasa $\mathrm{kg} \mathrm{d}^{-1}$. Letras diferentes en la misma fila indican diferencias significativas $(\mathrm{p}<0,05)$ según prueba de Tukey / ESM: standard error of the mean of the treatments. GLC: milk corrected for $4 \%$ fat; GLC: $(0.4$ x PLT) + 15 x kg G. PLT: total milk production, $\mathrm{G}$ : fat $\mathrm{kg} \mathrm{d}^{-1}$. Different letters in the same row indicate significant differences $(\mathrm{p}<0.05)$ according to Tukey's test. 
Cuadro 6. Calidad composicional de la leche vendible de vacas Gyr x Pardo Suizo de segundo parto en diferentes tercios de lactancia en pastoreo de Guinea, cv. Tanzania (Megathyrsus maximus) en función de la intensidad de pastoreo y el tercio de lactancia en San Diego, Departamento del César. Colombia. Septiembre-octubre, 2013.

Table 6. Compositional quality of the saleable milk of Gyr x Brown Swiss cows of second birth in different thirds stages of lactation in Guinea cv. Tanzania (Megathyrsus maximus) depending on the intensity of grazing and third of lactation in San Diego, Cesar Deparment. Colombia. September-October, 2013.

\begin{tabular}{|c|c|c|c|c|c|}
\hline \multirow[t]{2}{*}{ Variable } & \multicolumn{3}{|c|}{ Intensidad de pastoreo (animales ha $^{-1}$ ) } & \multirow[b]{2}{*}{ ESM } & \multirow[b]{2}{*}{$P$} \\
\hline & Baja $(1,0)$ & Media $(2,0)$ & Alta $(3,0)$ & & \\
\hline Sólidos totales (\%) & 13,58 & 13,53 & 13,24 & 0,98 & 0,53 \\
\hline Proteína (\%) & 3,41 & 3,50 & 3,41 & 0,22 & 0,41 \\
\hline Grasa $(\%)$ & 4,67 & 4,54 & 4,35 & 0,92 & 0,58 \\
\hline Lactosa $(\%)$ & 4,58 & 4,56 & 4,56 & 0,15 & 0,87 \\
\hline Minerales (\%) & 0,91 & 0,91 & 0,90 & 0,03 & 0,86 \\
\hline \multirow[t]{2}{*}{$\operatorname{NUL}\left(\mathrm{mg} \mathrm{dl}^{-1}\right)$} & 14,88 & 17,24 & 15,88 & 3,75 & 0,18 \\
\hline & \multicolumn{3}{|c|}{ Tercio de lactancia } & & \\
\hline Variable & Primer & Segundo & Tercero & ESM & $P$ \\
\hline Sólidos totales (\%) & 13,04 & 13,47 & 13,84 & 0,31 & 0,06 \\
\hline Proteína $(\%)$ & 3,37 & 3,44 & 3,51 & 0,07 & 0,19 \\
\hline Grasa $(\%)$ & 4,18 & 4,53 & 4,86 & 0,27 & 0,09 \\
\hline Lactosa $(\%)$ & 4,57 & 4,59 & 4,56 & 0,03 & 0,81 \\
\hline Minerales (\%) & 0,91 & 0,91 & 0,91 & 0,04 & 0,97 \\
\hline $\mathrm{NUL}\left(\mathrm{mg} \mathrm{dl}^{-1}\right)$ & 15,18 & 16,53 & 16,29 & 0,98 & 0,51 \\
\hline
\end{tabular}

ESM: error estándar de la media de los tratamientos. NUL: nitrógeno ureico en leche. Letras diferentes en la misma fila indican diferencias significativas $(\mathrm{p}<0,05)$ según prueba de Tukey / ESM: standard error of the mean of the treatments. NUL: ureic nitrogen in milk. Different letters in the same row indicate significant differences $(\mathrm{p}<0.05)$ according to Tukey's test.

en las intensidades intermedia $\left(2,0\right.$ animales $\left.\mathrm{ha}^{-1}\right)$ y alta $\left(3,0\right.$ animales $\left.\mathrm{ha}^{-1}\right)$ de pastoreo, pero los índices de los productos y sustratos individuales fueron similares $(\mathrm{p}>0,05)$ entre intensidades de pastoreo. En la intensidad media de pastoreo, el índice de aterogenicidad de la leche fue menor $(\mathrm{p}<0,05)$ y el índice de trombogenicidad tendió $(\mathrm{p}<0,10)$ a ser menor comparado con las otras intensidades (Cuadro 7).

El tercio de lactancia afectó la concentración de AG en la grasa de la leche de las vacas. La sumatoria de la concentración de los AG C12, C14 y C16 tendió a ser mayor (p<0,10) en las vacas de segundo tercio de lactancia. Las concentraciones de los ácidos grasos caproico (C6:0), linoleico (C18:2) y linolénico (C18:3) fueron mayores $(\mathrm{p}<0,05)$ en las vacas de primer tercio de lactancia.

Los restantes AG individuales, el ALC (c9 t11), los ácidos grasos según la saturación y el índice de actividad de la delta 9 desaturasa y de los productos y sustratos individuales en la grasa de la leche de las vacas no variaron ( $>0,05)$ debido al tercio de lactancia. Lo mismo ocurrió con el índice de aterogenicidad y trombogenicidad $(\mathrm{p}>0,05)($ Cuadro 8$)$. 
Cuadro 7. Perfil de ácidos grasos en la grasa de la leche vendible de vacas Gyr x Pardo Suizo de segundo parto en diferentes tercios de lactancia en pasto Guinea cv. Tanzania (Megathyrsus maximus) manejado con intensidades de pastoreo contrastantes en San Diego, Departamento del César, Colombia. Septiembre-octubre, 2013.

Table 7. Fatty acid profile in fat of saleable milk of Gyr x Brown Swiss cows of second birth in different thirds of lactation in Guinea cv. Tanzania (Megathyrsus maximus) grass managed with contrasting grazing intensities in San Diego, Cesar Deparment. Colombia. September-October, 2013.

\begin{tabular}{|c|c|c|c|c|c|}
\hline \multirow[t]{3}{*}{ Ácidos grasos (AG) } & \multicolumn{3}{|c|}{ Intensidad de pastoreo (animales ha ${ }^{-1}$ ) } & \multirow[b]{2}{*}{ ESM } & \multirow[b]{2}{*}{$\mathrm{P}$} \\
\hline & Baja $(\mathbf{1 , 0 )}$ & Media $(2,0)$ & Alta $(3,0)$ & & \\
\hline & \multicolumn{5}{|c|}{$\mathrm{mg} \mathrm{g}^{-1} \mathrm{AG}$} \\
\hline $\mathrm{C} 4: 0$ & 20,5 & 20,5 & 19,7 & 3,03 & 0,65 \\
\hline C6:0 & 17,2 & 16,8 & 16,6 & 1,42 & 0,42 \\
\hline $\mathrm{C} 8: 0$ & 10,3 & 10,2 & 9,9 & 1,2 & 0,57 \\
\hline $\mathrm{C} 10: 0$ & 21,7 & 21,4 & 20,8 & 3,53 & 0,77 \\
\hline $\mathrm{C} 12: 0$ & 26,1 & 26,0 & 24,9 & 4,05 & 0,65 \\
\hline $\mathrm{C} 14: 0$ & 105,1 & 101,4 & 101,5 & 9,17 & 0,39 \\
\hline $\mathrm{C} 14: 1 \mathrm{c} 9$ & 4,7 & 6,4 & 5,0 & 2,62 & 0,13 \\
\hline $\mathrm{C} 15: 0$ & 12,8 & 11,7 & 12,0 & 3,70 & 0,67 \\
\hline $\mathrm{C} 16: 0$ & 324,1 & 304,1 & 308,8 & 30,27 & 0,12 \\
\hline $\mathrm{C} 12: 0+\mathrm{C} 14: 0+\mathrm{C} 16: 0$ & 455,3 & 431,5 & 435,2 & 10,71 & 0,06 \\
\hline $\mathrm{C} 16: 1 \mathrm{c} 9$ & 11,5 & 12,5 & 13,6 & 4,63 & 0,41 \\
\hline $\mathrm{C} 17: 0$ & 5,7 & 5,7 & 4,9 & 3,20 & 0,70 \\
\hline C18:0 & 123,6 & 117,9 & 121,7 & 18,81 & 0,65 \\
\hline $\mathrm{C} 18: 1 \mathrm{c} 9$ & $192,2^{\mathrm{b}}$ & $211,0^{\mathrm{a}}$ & $202,5^{\mathrm{ab}}$ & 22,32 & 0,05 \\
\hline C18:1 t11(ATV) & 34,7 & 38,9 & 38,6 & 7,89 & 0,21 \\
\hline C18:2 c9 c12 (AL) & $7,1^{\mathrm{b}}$ & $6,7^{\mathrm{b}}$ & $9,0^{\mathrm{a}}$ & 1,28 & 0,01 \\
\hline C18:2 c9 t11 (ALC) & $12,3^{\mathrm{b}}$ & $15,5^{\mathrm{a}}$ & $13,7^{\mathrm{ab}}$ & 3,00 & 0,008 \\
\hline C18:3 c9 c12 c15 (ALN) & $5,8^{\mathrm{ab}}$ & $5,3^{\mathrm{b}}$ & $6,2^{\mathrm{a}}$ & 0,79 & 0,01 \\
\hline Relación AL/ALN & $1,2^{\mathrm{b}}$ & $1,3^{\mathrm{b}}$ & $1,5^{\mathrm{a}}$ & 1,33 & 0,03 \\
\hline AG según saturación & \multicolumn{5}{|c|}{$\mathrm{mg} \mathrm{g}^{-1} \mathrm{AG}$} \\
\hline Saturados & $670,0^{\mathrm{a}}$ & $638,6^{\mathrm{b}}$ & $644,7^{\mathrm{ab}}$ & 36,15 & 0,03 \\
\hline Insaturados & $311,5^{\mathrm{b}}$ & $341,7^{\mathrm{a}}$ & $335,9^{\mathrm{ab}}$ & 34,98 & 0,03 \\
\hline Monoinsaturados & $283,1^{\mathrm{b}}$ & $310,1^{\mathrm{a}}$ & $304,0^{\mathrm{ab}}$ & 31,41 & 0,03 \\
\hline Poliinsaturados & 28,4 & 31,6 & 31,9 & 4,83 & 0,06 \\
\hline AG según origen & \multicolumn{5}{|c|}{$\mathrm{mg} \mathrm{g}^{-1} \mathrm{AG}$} \\
\hline De novo $(4 \mathrm{a}<16 \mathrm{C})$ & 237,8 & 234,0 & 231,7 & 16,1 & 0,62 \\
\hline Preformados (> 16 C) & 419,4 & 442,1 & 440,2 & 25,2 & 0,07 \\
\hline Índice delta 9 desaturasa & $0,27^{\mathrm{b}}$ & $0,30^{\mathrm{a}}$ & $0,29^{\mathrm{ab}}$ & 0,03 & 0,03 \\
\hline C14:1/C14:0 & 0,04 & 0,06 & 0,04 & 0,009 & 0,13 \\
\hline C16:1/C16:0 & 0,03 & 0,04 & 0,04 & 0,005 & 0,24 \\
\hline C18:1/C18:0 & 1,61 & 1,83 & 1,71 & 0,11 & 0,19 \\
\hline CLA/ATV & 0,36 & 0,41 & 0,36 & 0,03 & 0,22 \\
\hline Índice aterogenicidad & $2,53^{\mathrm{a}}$ & $2,17^{\mathrm{b}}$ & $2,25^{\mathrm{ab}}$ & 0,13 & 0,02 \\
\hline Índice trombogenicidad & 3,47 & 3,01 & 3,10 & 0,19 & 0,06 \\
\hline
\end{tabular}

ATV: ácido transvaccénico. AL: ácido linoleico. ALC: ácido linolénico conjugado. ALN: ácido linolénico. ESM: error estándar de la media de los tratamientos. Letras diferentes en la misma fila indican diferencias significativas $(\mathrm{p}<0,05)$ según prueba de Tukey / ATV: transvaccenic acid. AL: linoleic acid. ALC: conjugated linolenic acid. ALN: linolenic acid. ESM: standard error of the mean of the treatments. Different letters in the same row indicate significant differences $(\mathrm{p}<0.05)$ according to Tukey's test. 
Cuadro 8. Perfil de ácidos grasos en la grasa de la leche vendible de vacas Gyr x Pardo Suizo de segundo parto en diferentes tercios de lactancia en tres intensidades de pastoreo de Guinea cv. Tanzania (Megathyrsus maximus) en San Diego, Departamento del César, Colombia. Septiembre-octubre, 2013.

Table 8. Fatty acid profile in fat saleable milk of Gyr x Brown Swiss cows of second birth in different thirds stages of lactation in three grazing intensities of Guinea cv. Tanzania (Megathyrsus maximus) in San Diego, Cesar Department, Colombia. September-October, 2013.

\begin{tabular}{|c|c|c|c|c|c|}
\hline \multirow[b]{3}{*}{ Ácidos grasos (AG) } & \multicolumn{3}{|c|}{ Tercios de lactancia } & \multirow[b]{2}{*}{ ESM } & \multirow[b]{2}{*}{$P$} \\
\hline & Primer & Segundo & Tercero & & \\
\hline & & & $\mathrm{mg} \mathrm{g}^{-1} \mathrm{AG}$ & & \\
\hline $\mathrm{C} 4: 0$ & 20,6 & 18,9 & 21,2 & 0,60 & 0,08 \\
\hline C6:0 & $17,6^{\mathrm{a}}$ & $15,8^{\mathrm{b}}$ & $17,3^{\mathrm{ab}}$ & 0,57 & 0,0007 \\
\hline $\mathrm{C} 8: 0$ & 10,6 & 9,7 & 10,0 & 0,21 & 0,10 \\
\hline C10:0 & 21,9 & 21,3 & 20,6 & 0,21 & 0,53 \\
\hline $\mathrm{C} 12: 0$ & 26,2 & 26,3 & 24,5 & 0,52 & 0,32 \\
\hline C14:0 & 104,1 & 102,0 & 101,8 & 0,41 & 0,70 \\
\hline $\mathrm{C} 14: 1 \mathrm{c} 9$ & 5,5 & 5,7 & 4,9 & 0,26 & 0,64 \\
\hline C15:0 & 11,6 & 11,5 & 13,3 & 0,64 & 0,26 \\
\hline $\mathrm{C} 16: 0$ & $302,7^{b}$ & $325,9^{\mathrm{a}}$ & $308,4^{\mathrm{ab}}$ & 7,34 & 0,05 \\
\hline $\mathrm{C} 12: 0+\mathrm{C} 14: 0+\mathrm{C} 16: 0$ & 433,1 & 454,2 & 434,7 & 7,57 & 0,06 \\
\hline $\mathrm{C} 16: 1$ & 11,7 & 11,5 & 14,4 & 0,93 & 0,13 \\
\hline $\mathrm{C} 17: 0$ & 5,8 & 5,3 & 5,1 & 0,20 & 0,77 \\
\hline C18:0 & 121,7 & 120,9 & 120,6 & 1,77 & 0,98 \\
\hline $\mathrm{C} 18: 1 \mathrm{c} 9$ & 205,5 & 196,1 & 204,1 & 3,24 & 0,40 \\
\hline C18:1 t11 (ATV) & 38,2 & 35,6 & 38,4 & 0,13 & 0,51 \\
\hline C18:2 c9 c12 (AL) & $8,0^{\mathrm{a}}$ & $6,9^{\mathrm{b}}$ & $7,8^{\mathrm{ab}}$ & 0,35 & 0,02 \\
\hline C18:2 c9 t11 (ALC) & 13,5 & 13,6 & 14,4 & 0,27 & 0,62 \\
\hline C18:3 c9 c12 c15 (ALN) & $6,2^{\mathrm{a}}$ & $5,3^{\mathrm{b}}$ & $5,8^{\mathrm{ab}}$ & 0,28 & 0,005 \\
\hline Relación AL/ALN & 1,3 & 1,3 & 1,3 & 0,02 & 0,74 \\
\hline AG según saturación & & & $\mathrm{mg} \mathrm{g}^{-1} \mathrm{AG}$ & & \\
\hline Saturados & 646,4 & 660,9 & 645,9 & 4,54 & 0,37 \\
\hline Insaturados & 334,7 & 319,9 & 334,5 & 4,50 & 0,35 \\
\hline Monoinsaturados & 303,7 & 290,2 & 303,4 & 4,17 & 0,34 \\
\hline Poliinsaturados & 31,3 & 29,7 & 31,3 & 0,33 & 0,60 \\
\hline AG según origen & & & $\mathrm{mg} \mathrm{g}^{-1} \mathrm{AG}$ & & \\
\hline De novo $(4 \mathrm{a}<16 \mathrm{C})$ & 238,6 & 231,1 & 233,8 & 4,42 & 0,48 \\
\hline Preformados (> 16 C) & 439,8 & 438,1 & 423,8 & 7,51 & 0,26 \\
\hline Índice delta 9 desaturasa & 0,29 & 0,28 & 0,29 & 0,004 & 0,33 \\
\hline C14:1/C14:0 & 0,05 & 0,06 & 0,04 & 0,006 & 0,66 \\
\hline C16:1/C16:0 & 0,03 & 0,03 & 0,04 & 0,004 & 0,07 \\
\hline C18:1/C18:0 & 1,72 & 1,68 & 1,75 & 0,08 & 0,83 \\
\hline CLA/ATV & 0,36 & 0,39 & 0,38 & 0,02 & 0,51 \\
\hline Indice aterogenicidad & 2,26 & 2,45 & 2,25 & 0,09 & 0,22 \\
\hline Indice trombogenicidad & 3,05 & 3,42 & 3,10 & 0,13 & 0,12 \\
\hline
\end{tabular}

ATV: ácido transvaccénico. AL: ácido linoleico. ALC: ácido linolénico conjugado. ALN: ácido linolénico. ESM: error estándar de la media de los tratamientos. Letras diferentes en la misma fila indican diferencias significativas $(\mathrm{p}<0,05)$ según prueba de Tukey / ATV: transvaccenic acid. AL: linoleic acid. ALC: conjugated linolenic acid. ALN : linolenic acid. ESM: standard error of the mean of the treatments. Different letters in the same row indicate significant differences $(p<0.05)$ according to Tukey's test. 


\section{Discusión}

El pasto Guinea cv. Tanzania fue la gramínea dominante en la composición botánica de la vegetación en las pasturas incluidas en las tres intensidades de pastoreo evaluadas; por lo tanto, se asume que la respuesta animal medida en términos de cantidad y composición de la leche, se debió principalmente a las diferentes ofertas y consumo de forraje del pasto Guinea cv. Tanzania. Por otra parte, las tres intensidades de pastoreo $(1,0 ; 2,0$ y 3,0 animales ha ${ }^{-1}$ ) utilizadas, resultaron en ofertas de forraje contrastantes (9 a $\left.30 \mathrm{~kg} \mathrm{MSV} 100 \mathrm{~kg}^{-1} \mathrm{PV} \mathrm{día}^{-1}\right)$. La oferta más baja (o la intensidad de pastoreo más alta aplicada) posiblemente no fue limitante para el consumo de vacas en pastoreo, porque representó una oferta de 2,7 veces más alta para lograr un consumo máximo de $3,3 \mathrm{~kg} \mathrm{MS} 100 \mathrm{~kg}^{-1}$ PV día ${ }^{-1}$ en vacas mestizas con pastos tropicales sin suplementación (Aroeira et al., 1999), lo cual puede explicar la similar producción y concentración de los componentes de la leche en las diferentes intensidades de pastoreo.

En lecherías especializadas se han evaluado el efecto de la oferta de forraje sobre la producción y composición de la leche. Los resultados de esos estudios indicaron que la oferta de forraje o intensidad de pastoreo es la variable que más afecta la producción de leche por animal y la concentración de proteína en la leche, debido a un mayor consumo de energía (O’Brien et al., 1997; Escobar y Carulla, 2003; Bargo et al., 2006; Mojica et al., 2009). Se observó un aumento de 0,3\% en la concentración de proteína en la leche por cada MJ de energía metabolizable adicional proveniente del forraje, cuando la proteína de la dieta era la apropiada (Stockdale, 1994).

Las intensidades de pastoreo utilizadas en el pasto Guinea cv. Tanzania no afectaron la concentración de extracto etéreo ni variaron en forma significativa los contenidos de AG totales y de AG individuales del pasto. Sin embargo, la tendencia a incrementar el contenido de ácido linoleico (C18:2 c9 c12) con la intensidad de pastoreo, influyó en el aporte de precursores de ALC (linoleico + linolénico), lo cual concuerda con el estudio de Mojica et al. (2019), donde el pasto Guinea cv. Tanzania manejado con intensidad alta $\left(3,0\right.$ animales ha $\left.{ }^{-1}\right)$ de pastoreo presentó mayores aportes de precursores de ALC en comparación con el pasto Brachiaria híbrido Mulato II, lo que generó una mayor concentración de ALC en la grasa de la leche de vacas Gyr x Pardo Suizo. Adicionalmente, se ha identificado que el pasto Guinea cv. Tanzania tiene un mayor contenido de precursores de ALC en comparación con otras gramíneas tropicales evaluadas a diferentes edades de rebrote (Mojica et al., 2017). Estos resultados sugieren que la utilización de pasto Guinea cv. Tanzania o manejado en intensidades de pastoreo de 3,0 animales ha $^{-1}$, con aportes incrementales de forraje en dietas con suplementación, podría aumentar la concentración de ALC en la grasa de la leche de las vacas, teniendo en cuenta los resultados de otros estudios donde se ha evaluado el efecto de la suplementación en vacas en pastoreo sobre el perfil de AG en leche de vacas (Castro-Hernández et al., 2014; Prieto-Manrique et al., 2016a).

El ácido palmítico (C16:0) fue el principal ácido graso en la grasa de la leche de las vacas que pastaron Guinea cv. Tanzania, manejado con diferentes intensidades de pastoreo (datos no presentados), lo cual coincide con otros estudios realizados con gramíneas tropicales (Mojica et al., 2013; Khan et al., 2015; Prieto-Manrique et al., 2016b). El C16:0 en la leche proviene de la dieta, síntesis de novo, movilización del tejido adiposo y microorganismos ruminales (Barber et al., 1997; Neville y Picciano, 1997). Se ha identificado que su concentración en la grasa de la leche se asocia positivamente con el aporte de la dieta (Warnjets et al., 2008) y en las diferentes intensidades de pastoreo el ácido palmítico (C16:0) fue el principal ácido graso en el pasto Tanzania.

El ácido esteárico (C18:0) en la grasa de la leche proviene de la biohidrogenación ruminal del ácido linoleico (C18:2) y linolénico (C18:3) (Chilliard y Ferlay, 2004), el aporte de microorganismos ruminales (Bas et al., 2003; Varadyova et al., 2008) y la dieta (Dohme et al., 2004). En este estudio, la concentración de ácido esteárico (C18:0) en la grasa de la leche de las vacas fue similar en las tres intensidades de pastoreo, lo que indica que no hubo diferencias en la biohidrogenación ruminal de los ácidos grasos linoleico y linolénico. Por otra parte, la concentración de AG de síntesis de novo fue similar en la grasa de la leche de las vacas en pasto Guinea cv. 
Tanzania manejado con diferentes intensidades de pastoreo, lo cual podría estar asociado a valores similares de fibra (FDN) en el forraje en oferta (Jenkins y McGuire, 2006; Calvache y Navas, 2012). La fermentación de la fibra por las bacterias en el rumen produce acetato y butirato que son los precursores de los ácidos grasos de novo en la grasa de la leche (Månsson, 2008).

En la intensidad alta $\left(3,0\right.$ animales ha $\left.{ }^{-1}\right)$ de pastoreo la concentración de ALC (c9 t11) en la grasa de la leche de las vacas fue mayor, lo cual podría estar relacionada con el mayor contenido de ácido linoleico, precursores (linoleico + linolénico) de ALC y mayor relación de ácido linoleico/linolénico en el forraje en oferta. Estos resultados son relevantes, debido a que el contenido de ALC en la leche se asocia principalmente al consumo total de sus precursores (ácido linoleico + linolénico) (Mohammed et al., 2009; León 2011; Shingfield et al., 2013), de los cuales, a partir de la biohidrogenación por las bacterias ruminales, se producen los diversos isómeros de ALC, incluyendo cis 9 trans11, y ATV en el rumen (Prieto-Manrique, 2016a). El ALC cis 9 trans 11 y el ATV producido en el rumen, se dirigen a la glándula mamaria, pero este último AG es utilizado para la síntesis endógena de la mayoría de este ALC presente en la leche (Bauman et al., 2006). Adicionalmente, Troegeler-Meynadier et al. (2003) encontraron que en la presencia de los dos ácidos grasos (linoleico y linolénico) precursores de ALC (c9 t11) en la dieta de los animales, las bacterias ruminales tienen preferencia por la biohidrogenación del ácido linoleico para producir ácido transvaccénico. Esto sugiere que una mayor relación C18:2/C18:3 en la dieta genera un aumento en el contenido de ALC (c9 t11) en la grasa de la leche.

La disminución de la producción de leche a medida que avanzó la lactancia estuvo de acuerdo con la curva de producción a través de la lactancia en vacas doble propósito (Osorio y Segura, 2005; Botero y Vertel, 2006). Por otra parte, en este estudio la concentración de los componentes en la leche fue similar en los tercios de lactancia, pero fue evidente la tendencia a que la concentración de sólidos totales y grasa aumentara, a medida que avanzó la lactancia, tal como se ha reportado en otros estudios con vacas lactantes de sistemas doble propósito (Mojica et al., 2013).

En este estudio, no se presentó una tendencia clara de disminución o aumento en la concentración de ácidos grasos de la leche debido al tercio de lactancia. La literatura revisada indica que los ácidos grasos derivados de la síntesis de novo se incrementan y los ácidos grasos preformados se reducen, a partir de una menor movilización de tejidos corporales, a medida que la lactancia progresa, lo cual está asociado a un balance energético positivo en los animales (Palmquist et al., 1993; Stoop et al., 2009; Bilal et al., 2014). Por otra parte, la concentración de ALC (c9 t11) en la grasa de la leche de las vacas fue similar en los tercios de lactancia, esto contrasta con estudios con vacas de lecherías especializadas alimentadas con pastos de zonas templadas, en los cuales se encontró que la concentración de ALC (c9 t11) era mayor en vacas de segundo y tercer tercio que en vacas de primer tercio (Kay et al., 2005; Stoop et al., 2009; Vargas et al., 2013). El mayor contenido de ALC en la leche de las vacas conforme la lactancia progresa se ha explicado por una mayor producción de ATV como producto de una incompleta biohidrogenación de los AG precursores de ALC, debido a un mayor consumo y a una mayor tasa de pasaje de alimento en los animales (Kay et al., 2005).

La leche producida en las tres intensidades de pastoreo en pasto Guinea cv. Tanzania, presentaron mayores concentraciones de C8:0, C10:0, C12:0, C14:0, C16:0, concentraciones similares de C18:3 y ALC (c9 t11) y menores concentraciones de C18:0, C18:1, C18:2, en comparación con el perfil de ácidos grasos (promedio) en leche proveniente de sistemas especializados con forrajes templados en Colombia (Rico et al., 2007; León, 2011; Gastón et al., 2014; Parales, 2015).

La leche producida en el pasto Guinea cv. Tanzania manejado con intensidades media y alta de pastoreo presentó las mayores concentraciones de ALC (c9 t11), de ácido oleico (C18:1) y menor índice de aterogenicidad. Estas modificaciones en la grasa de la leche debidas a la intensidad de pastoreo del pasto Guinea cv. Tanzania pueden traer consigo potenciales efectos positivos en salud la humana, en términos de reducciones de colesterol LDL y triglicéridos, y a aumentos de colesterol HDL debidos al ácido oleico (C18:1) (López, 2010; Haeiwa et al., 
2014) y menor probabilidad en la formación de ateroesclerosis (Ulbricht y Southgate, 1991). La concentración de ALC en la carga media (15,5 $\left.\mathrm{mg} \mathrm{g}^{-1} \mathrm{AG}\right)$, posiblemente generaría un efecto positivo en la reducción en el riesgo $(43 \%)$ de infarto de miocardio no fatal en humanos, que se ha asociado a consumos de $0,33 \mathrm{~g} \mathrm{~d}^{-1} \mathrm{de}^{\mathrm{ALC}}$ con una concentración de 15,8 mg de ALC en la grasa de la leche (Smith et al., 2015).

Analizar cada ácido graso en forma individual no es suficiente para determinar su efecto nutraceútico, por lo que se debe considerar la relación entre ácidos grasos (Ortega et al., 2013). En forma general, la reducción en la relación ácido linoleico/linolénico en las dietas en humanos favorece la salud, y disminuye el riesgo de presentación de enfermedades (Gómez et al., 2011). Por ejemplo, se ha sugerido que la relación ácido linoleico/linolénico en los alimentos debería ser cercana a 2,5 para reducir la proliferación celular rectal en pacientes con cáncer (Simopoulos, 2002). Bajo este punto de vista, en este estudio la leche producida con Guinea cv. Tanzania en las diferentes intensidades de pastoreo ofrecería efectos benéficos sobre la salud humana por su baja relación ácido linoleico/ linolénico $(1,3$ a 1,5$)$.

\section{Conclusiones}

El efecto de modificar la oferta del cultivar Tanzania mediante diferentes intensidades de pastoreo que resultaron en ofertas de forraje no limitantes para el consumo de los animales, no afectó la calidad del forraje en oferta, la producción de leche individual ni la calidad composicional de la leche. Sin embargo, las concentraciones de ácido oleico (C18:1), ácido linoleico conjugado (c9 t11), y ácidos insaturados, fueron mayores y el índice de aterogenicidad fue menor en la grasa de la leche, cuando el pasto se manejó con intensidades medias y altas de pastoreo, lo que podría otorgar a la leche potenciales efectos saludables. El tercio de lactancia tuvo efecto en producción de leche (reducción a medida que aumentaban los días de lactancia), pero no afectó en forma consistente la calidad composicional ni el perfil de ácidos grasos en la grasa de la leche.

\section{Nota de comité de bioética}

La investigación contó con la aprobación del comité de bioética de la Facultad de Medicina Veterinaria y de Zootecnia de la Universidad Nacional de Colombia sede Bogotá (Acta 08, 6 septiembre del 2012), en lo relacionado con el cumplimiento de las normas nacionales e internacionales de protección de los derechos de los animales y el uso y cuidado de animales para la experimentación.

\section{Agradecimientos}

Los autores expresan agradecimiento a la Corporación Colombiana de Investigación Agropecuaria (AGROSAVIA) por financiar este estudio.

\section{Literatura citada}

Aguilar, O.X., B. Moreno, M.L. Pabón, y J. Carulla. 2009. Efecto del consumo de kikuyo (Pennisetum clandestinum) o raigrás (Lolium hibridum) sobre la concentración de ácido linoléico conjugado y el perfil de ácidos grasos de la grasa láctea. Livest. Res. Rural Dev. 21(4):49. http://www.lrrd.org/lrrd21/4/agui21049.htm (consultado 15 ene. 2018). 
Allen, M.S. 2000. Effects of diet on short-term regulation of feed intake by lactating dairy cattle. J. Dairy Sci. 83:1598-1624. doi:10.3168/jds.S0022-0302(00)75030-2

Amezquita, M. 1999. Diseño y análisis de ensayos para evaluación de pasturas en fincas. CIAT, COL. http://ciat-library.ciat. cgiar.org/forrajes_tropicales/pdf/4th/DisenoYanalisisDeEnsayos.pdf (consultado 15 ene. 2018).

AOAC (Association Official of Analytical Chemistry). 2010. Official methods of analysis of AOAC international. 18th ed. AOAC Int., MD, USA.

Aroeira, L.J.M., F.C.F. Lopes, F. Deresz, R.S. Verneque, M.S. Dayrell, L.L. De-Matos, H. Maldonado-Vasquez, and A. Vittori. 1999. Pasture availability and dry matter intake of lactating crossbred cows grazing elephant grass (Pennisetum purpureum, Schum.). Anim. Feed. Sci. Technol. 78:313-324. doi:10.1016/S0377-8401(98)00270-3

Barber, M.C., R.A. Clegg, M.T. Travers, and R.G. Vernon. 1997. Lipid metabolism in the lactating mammary gland. Biochim. Biophys. Acta 1347(2-3):101-126. doi:10.1016/s0005-2760(97)00079-9

Bargo, F., J. Delahoy, G. Schroeder, and L. Muller. 2006. Milk fatty acid composition of dairy cows grazing at two pasture allowances and supplemented with different levels and sources of concentrate. Anim. Feed Sci. Technol. 125:17-31. doi:10.1016/j.anifeedsci.2005.05.010

Bas, P., H. Archimède, A. Rouzeau, and D. Sauvant. 2003. Fatty acid composition of mixed-rumen bacteria: Effect of concentration and type of forage. J. Dairy Sci. 86:2940-2948. doi:10.3168/jds.S0022-0302(03)73891-0

Bauman, D.E., I.H. Mather, R.J. Wall and A.I. Lock. 2006. Major advances associated with the biosynthesis of milk. J. Dairy Sci. 89:1235-1243.

Bessa, R.J.B., J. Santos-Silva, J.M.R. Ribeiro, and A.B. Portugal. 2000. Retículo-rumen biohydrogenation and the enrichment of ruminant edible products with linoleic acid conjugated isomers. Livest. Prod. Sci. 63:201-211. doi:10.1016/S03016226(99)00117-7

Bilal, G., R. Cue, A. Mustafa, and J. Hayes. 2014. Effects of parity, age at calving and stage of lactation on fatty acid composition of milk Canadian Holsteins. Can. J. Anim. Sci. 94:401-406. doi:10.4141/cjas2013-172

Botero, L., y M. Vertel. 2006. Modelo matemático aplicado a la curva de lactancia en ganado vacuno doble propósito. Rev. MVZ. Córdoba 11(1):759-765. doi:10.21897/rmvz.461

Calvache, I., y A. Navas. 2012. Factores que influyen en la composición nutricional de la leche. Rev. Cienc. Anim. 5:73-85.

Castro-Hernández, H., F.F. González-Martínez, I.A. Domínguez-Vara, J.M. Pinos-Rodríguez, E. Morales-Almaráz, y R. VieyraAlberto. 2014. Efecto del nivel de concentrado sobre el perfil de ácidos grasos de la leche de vacas Holstein en pastoreo. Agrociencia 48:765-75

Chilliard, Y., and A. Ferlay. 2004. Dietary lipids and forages interactions on cow and goat milk fatty acid composition and sensory properties. Reprod. Nutr. Dev. 44:467-492. doi:10.1051/rnd:2004052

Corl, B., L. Baumgard, D. Dwyer, J. Griinari J., B. Phillips, and D. Bauman. 2001. The role of delta Delta (9)- desaturase in the production of cis-9, trans-11 CLA. J. Nutr. Biochem. 12:622-630. doi:10.1016/S0955-2863(01)00180-2

CORPOICA. 2017. Sistema experto modelos de adaptación y prevención agroclimática. CORPOICA, COL. http://www. corpoica.org.co:8086/NetCorpoicaMVC/SEMapa (consultado 10 ene. 2019).

Dhiman, T.R., G.R. Anand, L.D. Satter, and M.W. Pariza. 1999. Conjugated linoleic acid content of milk from cows fed different diets. J. Dairy Sci. 82:2146-2156. doi:10.3168/jds.S0022-0302(99)75458-5

Díaz, G., R. Gutiérrez, N. Pérez, S. Vega-y-León, M. González, G. Prado, G. Urbán, A. Ramírez, y M. Pinto. 2002. Detección de adulteraciones en la grasa de leche pasteurizada mexicana. Rev. Salud Anim. 24(1):54-59. 
Dilzer, A., and Y. Park. 2012. Implication of conjugated linoleic acid (CLA) in human health. Crit. Rev. Food Sci. Nutr. 5:488513. doi:10.1080/10408398.2010.501409

Dohme, F., A. Machmüller, F. Sutter, and M. Kreuzer. 2004. Digestive and metabolic utilization of lauric, myristic and stearic acid in cows, and associated effects on milk fat quality. Arch. Anim. Nutr. 58(2):99-116. doi:10.1080/00039420410001 667485

Elgersma, A., G. Ellen, H. van-der-Horst, H. Boer, P. Dekker, and S. Tamminga. 2004. Quick changes in milk fat composition from cows after transition from fresh grass to a silage diet. Anim. Feed Sci. Technol. 117:13-27. doi:10.1016/j. anifeedsci.2004.08.003

Escobar, A., y J. Carulla. 2003. Efecto de la oferta de forraje sobre los parámetros productivos y composicionales de la leche en la Sabana de Bogotá. Rev. Colomb. Cienc. Pecu. 16(4):67.

Fawcet, B., and J.E. Scott. 1960. A rapid and precise method for determination of urea. J. Clin. Pathol. 13:156-159. doi:10.1136/ jcp.13.2.156

Ferlay, A., B. Martin, P. Pradel, J.B. Coulon, and Y. Chilliard. 2006. Influence of grass-based diets on milk fatty acid composition and milk lipolytic system in Tarentaise and Montbeliarde cow breeds. J. Dairy Sci. 89:4026-4041 . doi:10.3168/jds.S00220302(06)72446-8

Gagliostro, G., A. Rodríguez, P. Pellegrini, P. Gatti, G. Musset, R. Castañeda, A. Colombo, e Y. Chilliard. 2006. Efectos del suministro de aceite de pescado solo o en combinación con aceite de girasol sobre las concentraciones de ácido linoleico conjugado (CLA) y omega 3 (n-3) en leche de cabra. Rev. Argent. Prod. Anim. 26:71-87.

Garcés, R., and M. Mancha. 1993. One-step lipid extraction and fatty acid methyl esters preparation from fresh plant tissue. Anal. Biochem. 211:139-143. doi:10.1006/abio.1993.1244

Gastón, A.C., M.L. Pabón, and J.E. Carulla. 2014. Concentration of trans-vaccenic and rumenic acids in the milk from grazing cows supplemented with palm oil, rice bran or whole cottonseed. Rev. Bras. Zootec. 43:315-326. doi:10.1590/S151635982014000600006

Gómez, C., L. Bermejo, and V. Loria. 2011. Importance of a balance omega 6/omega 3 ratio for the maintenance of health: nutritional recommendations. Nutr. Hosp. 26:323-329. doi:10.1590/S0212-16112011000200013

Haeiwa, H., T. Fujita, Y. Saitoh, and N. Miwa. 2014. Oleic acid promotes adaptability against oxidative stress in 3T3-L1 cells through lipohormesis. Mol. Cell. Biochem. 386:73-83. doi:10.1007/s11010-013-1846-9

Hurley, W.L., G.J. Warner, and R.R. Grummer. 1987. Changes in triglyceride fatty acid composition of mammary secretions during involution. J. Dairy Sci. 70:2406-2410. doi:10.3168/jds.S0022-0302(87)80302-8

Huth, P., and K. Park. 2012. Influence of dairy product and milk fat consumption on cardiovascular disease risk: A review of the evidence. Adv. Nutr. 3:266-285. doi:10.3945/an.112.002030

Jeffery, H.J. 1970. The length of change-over periods in change-over designs with grazing cattle. Aust. J. Exp. Agric. Anim. Husb. 10:691-693. doi:10.1071/EA9700691

Jenkins, T.C., and M.A. McGuire. 2006. Major advances in nutrition: impact on milk composition. J. Dairy Sci. 89:1302-1310. doi:10.3168/jds.S0022-0302(06)72198-1

Jutzeler, R., and P. Colombani. 2010. Grass-based ruminant production methods and human bioconversion of vaccenic acid and estimations of maximal dietary intake of conjugated linoleic acids. Int. Dairy J. 20:433-448. doi:10.1016/j. idairyj.2010.01.008 
Kay, J.K., W.J. Weber, C.E. Moore, D.E. Bauman, L.B. Hansen, H. Chester-Jones, B.A. Crooker, and L.H. Baumgard. 2005. Effects of week of lactation and genetic selection for milk yield on milk fatty acid composition in Holstein cows. J. Dairy Sci. 83:3886-3893. doi:10.3168/jds.S0022-0302(05)73074-5

Khan, N.A., M.W. Farooq, M. Ali, M. Suleman, N. Ahmad, S.M. Sulaiman, J.W. Cone, and W.H. Hendriks. 2015. Effect of species and harvest maturity on the fatty acids profile of tropical forages. J. Anim. Plant Sci. 25:739-746.

Kratz, M., T. Baars, and S. Guyenet. 2013. The relationship between high-fat dairy consumption and obesity, cardiovascular, and metabolic disease. Eur. J. Nutr. 52(1):1-24. doi:10.1007/s00394-012-0418-1

León, J.M. 2011. Efecto de la incorporación de leguminosas en pasturas de trópico alto sobre el contenido de ácido linoleico conjugado ALC en la leche. Tesis MSc., Universidad Nacional de Colombia, Bogotá, COL.

López, E. 2010. Health effects of oleic acid and long chain omega-3 fatty acids /EPA and DHA) enriched milks. A review of intervention studies. Pharmacol. Res. 61:200-207. doi:10.1016/j.phrs.2009.10.007

Månsson, H.L. 2008. Fatty acids in bovine milk fat. Food Nutr. Res. 52. doi:10.3402/fnr.v52i0.1821

McCarthy, B., L. Delaby, K.M. Pierce, F. Journot, and B. Horan. 2011. Meta-analysis of the impact of stocking rate on the productivity of pasture-based milk production systems. Animal 5:784-794. doi:10.1017/S1751731110002314

McDonald, K.A., J.W. Penno, J.A. Lancaster, and J.R. Roche. 2008. Effect of stocking rate on pasture production, milk production, and reproduction of dairy cows in pasture-based systems. J. Dairy Sci. 91:2151-2163. doi:10.3168/jds.20070630

Mohammed, R., C.S. Stanton, J.J. Kennelly, J.K. Kramer, J.F. Mee, D.R. Glimm, M. O’Donovan, and J.J. Murphy. 2009. Grazing cows are more efficient than zero-grazed and grass silage-fed cows in milk rumenic acid production. J. Dairy Sci. 92:3874-3893. doi:10.3168/jds.2008-1613

Mojica, J.E., E. Castro, J. Carulla, y C. Lascano. 2017. Efecto de la edad de rebrote sobre el perfil de ácidos grasos en gramíneas tropicales. Corpoica Cienc. Tecnol. Agropecu. 18:217-232.doi:10.21930/rcta.vol18_num2_art:623

Mojica, J.E., E. Castro, J. León, E. Cárdenas, M.L. Pabón, y J.E. Carulla. 2009. Efecto de la oferta de pasto kikuyo (Pennisetum clandestinum) sobre la producción y calidad composicional de la leche bovina. Livest. Res. Rural Dev. 21(1):1. http:// www.lrrd.org/lrrd21/1/moji21001.htm (consultado 10 ene. 2019).

Mojica, R.J.E, R.E. Castro, Z.J. Silva, H.C. Hanzel, y Q.L. García. 2013. Producción y calidad composicional de la leche en función de la alimentación en ganaderías doble propósito del departamento del Cesar. Corpoica, Bogotá, COL. doi:10.21930/978-958-740-164-6

Mojica-Rodríguez, J.E., E. Castro-Rincón, J.E. Carulla-Fornaguera, y C.E. Lascano-Aguilar. 2019. Perfil lipídico en leche de vacas en pastoreo de gramíneas en el trópico seco colombiano. Agron. Mesoam. 30:497-515. doi:10.15517/ am.v30i2.34723

Neville, M.C., and M.F. Picciano. 1997. Regulation of milk lipid secretion and composition. Annu. Rev. Nutr. 17:159-183. doi:10.1146/annurev.nutr.17.1.159

O’Brien, B., J.J. Murphy, J.F. Conolly, R. K. Mehra, P. Guinee, and J. Stakelum. 1997. Effect of altering the daily herbage allowance in mid lactation of the composition and processing characteristics of bovine milk. J. Dairy Res. 64:621-626. doi: $10.1017 /$ S0022029997002513

Ørskov, E.R., F.D. DeB-Howell, and F. Mould. 1980. The use of the nylon bag technique for the evaluation of feedstuffs. Trop. Anim. Prod. 5:295-213.

Ortega, R., J. Espinoza, E. Palacios, A. Palacios, O. Arjona, B. Murillo, y F. Rivera. 2013. Perfil de ácidos grasos en leche de vacas Chinampas (Bos taurus) alimentadas con forraje fresco de matorral sarcocaulescente o heno de alfalfa. Arch. Med. 


\section{5:45-51. doi:10.4067/S0301-732X2013000100008}

Osorio, M.M., y J.C. Segura. 2005. Factores que afectan la curva de lactancia de vacas Bos taurus x Bos indicus en un sistema doble propósito en el trópico húmedo de Tabasco, México. Téc. Pecu. Méx. 43(1):127-137.

Palmquist, D.L., A.D. Beaulieu, and D.M. Barbano. 1993. Feed and animal factors influencing milk fat composition. J. Dairy Sci. 76:1753-1771. doi:10.3168/jds.S0022-0302(93)77508-6

Parales, J. 2015. Efecto de la suplementación de aceites vegetales y sus mezclas sobre la fermentación ruminal y el perfil de ácidos grasos en leche. Tesis MSc., Universidad Nacional de Colombia, Bogotá, COL.

Prieto-Manrique, E., L. Mahecha-Ledesma, J. Ángulo-Arizala, y J.E. Vargas-Sánchez. 2016a. Efecto de la suplementación lipídica sobre ácidos grasos en leche de vaca, énfasis en ácido ruménico. Agron. Mesoam. 27:421-437. doi:10.15517/ am.v27i2.22022

Prieto-Manrique, E., J.E. Vargas-Sánchez, J. Ángulo-Arizala, y L. Mahecha-Ledesma. 2016b. Grasa y ácidos grasos en leche pastoreando cuatro sistemas de producción. Agron. Mesoam. 28:19-42. doi:10.15517/am.v28i1.22816

Pulido, J.I., M. Romero, S.T. Rivero, y O.A. Duarte. 2002. Atlas de los sistemas de producción bovina. Módulo Región Caribe. CORPOICA, Bogotá, COL.

Rego, O., A. Cabrita, H. Rosa, S. Anes, V. Duarte, A. Fonseca, C. Vouzela, F. Rocha, and R. Bessa. 2016. Changes in milk production and milk fatty acid composition of cows switched from pasture to a total mixed ration diet and back to pasture. Ital. J. Anim. Sci. 15:76-86. doi:10.1080/1828051X.2016.1141330

Rico, D.E. 2013. Recovery of normal ruminal biohydrogenation and the novo fatty acid synthesis following induction of milk fat depression in dairy cows. Ph.D. Diss., The Pennsylvania State University, PA, USA.

Rico, J.E., B. Moreno, M.L. Pabón, y J. Carulla. 2007. Composición de la grasa láctea de la sabana de Bogotá con énfasis en ácido ruménico - CLA cis-9, trans-11. Rev. Colomb. Cienc. Pecu. 20(1):30-39.

SAS Institute Inc. 2011. SAS/STAT Software version 9.3. SAS Institute Inc., Cary, NC, USA.

Shingfield, K.J., M. Bonnet, and N.D. Scollan. 2013. Recent developments in altering the fatty acid composition of ruminantderived foods. Animal 7:132-162. doi:10.1017/S1751731112001681

Simopoulos, A. 2002. The importance of the ratio of omega-6/omega-3 essential fatty acids. Biomed. Pharmacother. 56:365379. doi:10.1016/S0753-3322(02)00253-6

Smit, L., A. Baylin, and H. Campos. 2015. Conjugated linoleic acid in adipose tissue and risk of myocardial infarction. Am. J. Clin. Nutr. 92:34-40. doi:10.3945/ajen.2010.29524

Siri, P., Q. Sin, F. Hu, and R. Krauss. 2010. Meta-analysis of prospective cohort studies evaluating the association of saturated fat with cardiovascular disease. Am. J. Clin. Nutr. 91:535-546. doi:10.3945/ajcn.2009.27725

Soedamah-Muthu, S.S., E.L. Ding, W.K. Al-Delaimy, F.B. Hu, M.F. Engberink, W.C. Willett, and J.M. Geleijnse. 2011. Milk and dairy consumption and incidence of cardiovascular diseases and all-cause mortality: dose-response meta-analysis of prospective cohort studies. Am. J. Clin. Nutr. 93:158-171. doi:10.3945/ajen.2010.29866

Stanton, C., F. Lawless, G. Kjellmer, D. Harrington, R. Devery, J.F. Connolly, and J. Murphy. 1997. Dietary influences on bovine milk cis-9,trans-11-Conjugated Linoleic Acid content. J. Food Sci. 62:1083-1086. doi:10.1111/j.1365-2621.1997. tb15043.x

Stockdale, C.R. 1994. Effect of diet on the energy required to improve milk protein content in dairy cows. Proc. Aust. Soc. Anim. Prod. 20:378. 
Stoobs, T.H., and R.L. Sandland. 1972. The use of a latin square change - over design with dairy cows to detect differences in the quality of tropical pastures. Aust. J. Exp. Agric. 12:463-469. doi:10.1071/EA9720463

Stoop, W.M., H. Bovenhius, J.M.L. Heck, and J.A.M. Van-Arendock. 2009. Effect of lactation stage and energy status on milk fat composition of Holstein - Friesian cows. J. Dairy Sci. 92:1469-1478. doi:10.3168/jds.2008-1468

Toledo, J.M., y R. Schultze-Kraft. 1982. Metodología para la evaluación agronómica de pastos tropicales. En: J.M. Toledo, editor, Manual para la evaluación agronómica: Red internacional de evaluación de pastos tropicales. CIAT, Cali, COL. p. $91-110$.

Troegeler-Meynadier, M.A., M.C. Nicot, C. Bayourthe, R. Moncoulon, and F. Enjalbert. 2003. Effects of pH and concentrations of linoleic acid linolenic acids on extent and intermediates of ruminal biohydrogenation in vitro. J. Dairy Sci. 86:40544063. doi:10.3168/jds.S0022-0302(03)74017-X

Ulbricht, T.L., and D.A. Southgate. 1991. Coronary heart disease: seven dietary factors. Lancet 338:985-992. doi:10.1016/01406736(91)91846-M

Van-Soest, P.J., J. Roberton, and B.A. Lewis. 1991. Methods for dietary fiber, neutral detergent fiber, and nonstarch polysaccharides in relation to animal nutrition. J. Dairy Sci. 74:3583-3597. doi:10.3168/jds.S0022-0302(91)78551-2

Varadyova, Z., S. Kisidayová, P. Siroka, and D. Jalc. 2008. Comparison of fatty acid composition of bacterial and protozoal fractions in rumen. fluid of sheep fed diet supplemented with sunflower, rapeseed and linseed oils. Anim. Feed Sci. Technol. 144:44-54. doi:10.1016/j.anifeedsci.2007.09.033

Vargas, J.M., J.E. Mojica, M.R. Pabón, y J. Carulla. 2013. Oferta de pasto kikuyo (Pennisetum clandestinum), tercio de lactancia y perfil de ácidos grasos lácteos. Rev. MVZ Córdoba 18(Supl.):3681-3688. doi:10.21897/rmvz.135

Warnjets, J.L., P.H. Robinson, E. Galo, E.J. DePeters, and D. Howes. 2008. Effects of feeding supplemental palimitic acid (C16:0) on performance and milk fatty acid profile of lactating dairy cows under summer heat. Anim. Feed Sci. Technol. 140:241-257. doi:10.1016/j.anifeedsci.2007.03.004

Yamasaki, M., K. Kishihara, I. Ikeda, M. Sugano, and K. Yamada. 1999. A recommended esterification method for gas chromatographic measurement of conjugated linoleic acid. J. Am. Oil Chem. Soc. 76:933-938. doi:10.1007/s11746-9990109-0 